ORIGINAL ARTICLE

\title{
The Relationship Between Life Course Factors, Parental Demographics, Dental Coping Beliefs and Its Influence on Adolescents Dental Visit: a Cross Sectional Study
}

\author{
Srinivasan R.Samuel ${ }^{1}$, Sachin G.Khatri ${ }^{2}$, Shashidhar Acharya ${ }^{3}$, Snehal T.Patil ${ }^{4}$
}

\section{ABSTRACT}

BACKGROUND: Oral Disease is a multifactorial one that includes behavioral and cultural components, and the severity of the disease depends on regularity of dental visits. The purpose of the study was to evaluate the relationship between parental demographics, life course factors, dental coping beliefs with therecent dental attendance among adolescents in Udupi Taluk.

METHODS: Three hundred and fifty adolescents aged 16-19 years from four randomly selected schools in Udupi Taluk participated in this cross sectional study. Information was obtained regarding their parental demographics, their early life course, dental coping beliefs and recent dental attendance. Bivariate followed by multiple logistic regression analysis was performed to elicit variables which predict recent dental attendance.

RESULTS: Out of the 324 adolescents who completed the questionnaire, $25.3 \%$ reported visiting a dentist within a period of one year. Childhood dental visit, childhood dental experience, housing, internal and external locus of control and self-efficacy were significantly associated with recent dental visit ( $p<0.05)$. Participants who lived in cement/brick houses were 4.3 times more likely to visit a dentist within one year compared to those living in hut/mud/combined houses $(p<0.05)$. Adolescents with lower external $(O R=0.11, P<0.003)$ and low internal $(O R=0.05, P<0.001)$ locus of control had lower odds of visiting a dentist within a year when compared with those having higher locus of control.

CONCLUSION: Childhood financial hardships, childhood dental visits and experiences and dental coping beliefs affect dental attendance pattern during adolescence. These factors should be considered while tailoring interventions to promote the oral health and dental attendance behaviors of adolescents.

KEYWORDS:Coping beliefs, dental attendance, life course, locus of control, social class

DOI: http://dx.doi.org/10.4314/ejhs.v25i3.7

\footnotetext{
${ }^{1}$ Department of Public Health Dentistry, Thai Moogambigai Dental College and Hospital, Dr. M.G.R. Educational and Research Institute, Chennai, India

${ }^{2}$ Department of Public Health Dentistry, V.S.P.M. Dental College, Nagpur, India

${ }^{3}$ Department of Public Health Dentistry, Manipal College of Dental Sciences, Manipal University, Manipal, India

${ }^{4}$ Department of Public Health Dentistry, Sri Krishna Institute of Medical and Dental Sciences, Karad, India

Corresponding Author: Srinivasan Raj Samuel, Email: samuelrajsrinivasan@gmail.com
} 


\section{INTRODUCTION}

Experiences in early life leave an ineradicable imprint on an individual throughout his life; oral health is not an exception. Life course approach which helps researchers explore the effect of early life events throughout the individual's life was developed to understand the epidemiology of the disease better (1). Life course approach signifies the importance of biological and social experiences at different stages of life rather than at one point of time. It mainly refers to a "chain of circumstances" where exposure to one factor is connected to a chain of factors that get accumulated over the life course. This approach has been applied extensively to capture risk factors on chronic systemic diseases (2). Socioeconomic resources in the family of origin are considered to be the most important of all the life course factors which have a major impact on health (3). Many studies have explored how the imprint of childhood circumstances is expressed later in life regarding oral health, and these are consistent with the life course prospect $(4,5)$.

Dental care has sought increasingly into behavioral psychology for intervention models. Major models, namely, locus of control (LOC), self-efficacy and self-instructional techniques have highlighted the importance of individuals' thoughts, ideas and cognition in regulation of dental behavior and beliefs regarding factors affecting their oral health. These theories constitute the cornerstone for dental coping belief scale. Studies have explored the use of dental coping beliefs in finding its relation with oral hygiene, measuring cognitive changes and oral health behavior (6).

Dental care is the most common type of unmet health care need among adolescents; utilization of dental care is affected by age, gender and socio economic position as reported in the literature $(7,8)$. The most convenient place to obtain a large representative sample of adolescents is a school from the respective region and hence this study was conducted in randomly selected schools in Udupi Taluk. Udupi as a district was formed in 1997, with Udupi, Kundapura, Karkala and Talukas. Udupi Taluk, according to 2011 census, had a population of 529,$225 ; 28.9 \%$ urban and $71.1 \%$ rural. The schools in Udupi can be categorized as those in north and in south zones.,
South Zone has a total of 18 government high schools and 23 private schools.

Studies on the influence of life course factors and coping beliefs on adolescents dental visit pattern as such are relatively scarce and in India. Hence, the purpose of this research was to evaluate the relationship between parental demographics, life course factors, dental coping beliefs and 'recent' dental attendance among adolescents in Udupi Taluk.

\section{MATERIAL AND METHODS}

A cross sectional study was conducted on 350 adolescents of Udupi; Karnataka, aged 16-19 years from April to June, 2013. Six schools were chosen based on simple random sampling from a cohort of schools in South Zone of Taluk obtained from the district development officer. Adolescents between the age group of 16-19 years, who are permanent resident of Udupi with no serious life threatening diseases and who consented to participate were recruited in the study. Ethical approval was obtained from the IRB of Manipal University (IEC 160/2013). Permission from the head of the institution and written informed consent from the participants and their parents were obtained before the commencement of the study.

The sample size was calculated to be 320 at $80 \%$ power and alpha error of $5 \%$. Therefore, the questionnaire was administered to a total of 350 adolescents to compensate for non-response. The participants answered a self-administered questionnaire on parental demographics, life course factors, dental coping beliefs and 'recent' dental attendance. The native language of the district is Kannada; hence, the questionnaire was translated into this language. The questionnaire was back translated blindly into English to check its validity. Validity was checked by two experts who were fluent in both Kannada and English. When a difference of opinion was encountered, both mutually consented and reached an agreement; Cronbach's alpha was assessed to check for the internal consistency of dental coping belief scale (DCBS) and life course questionnaire; it was found to be 0.77 and 0.68 respectively. The demographics included participants' ages, gender and parents' education and occupation. Parents' education was categorized as uneducated versus primary/secondary and higher (PUC)/degree level 
of education. Parents' occupation was classified according to the National Statistics Socioeconomic Status Classification (9).

Life course factors included questions regarding the type of house in which the participant lived when he/she was 10 years old, number of siblings when the participants were 10 years old, dental visit during childhood and his/her experience during the visit. Housing was categorized as specified by the Government of India as 'Kutcha' (mud/ thatched roof), 'Pucca' (cement/brick) and 'Partial Pucca' (combined) houses. Kutcha and Partial Pucca were combined into a single group during the analysis. The number of siblings the participant had when he/she was 10 years old was recorded as 'no siblings', 'one' and 'two or more than two'. Responses for dental visit during childhood and experience during the visit was dichotomized as 'yes' or 'no' and 'good' or 'bad' respectively. The participants reported their 'recent' dental attendance (RDA) in one of the three options: ' $<1$ year', '> 1 year' (also includes more than one year/ never) and 'symptom based visits'.

DCBS was adapted from Jacobs and Stewart 1976 (6). It is a 44 item scale with four main domains; 'Internal LOC' (15 questions), 'External LOC' (14 questions), 'Self-efficacy' (9 questions), 'Oral health beliefs' (6 questions). The responses were marked on a five point Likert scale ranging from strongly disagree to strongly agree. The dental coping beliefs were dichotomized based on the median values as high and low. Adolescents with median values greater than 33 for external locus of control were categorized as having high locus of control and less than 33 as low respectively. Similarly, internal locus of control (Median= 31), self-efficacy $($ Median=18) and oral health beliefs (Median=16) were categorized as high and low based on their median scores.

The data was analyzed using SPSS version 16.0 (Statistical Package for Social Sciences,
Chicago, IL). Bivariate analysis was performed using chi square test; multivariate analysis were performed using multiple logistic regression (enter method) with recent dental attendance as outcome measure. The result was considered significant if $p$ value $<0.05$, at $95 \%$ confidence interval.

\section{RESULTS}

Out of the 350 adolescents who filled out he questionnaire, 324 fully completed it and the response rate was $94 \%$. The mean age of respondents was $17.51 \pm 1.18$ years. Among the respondents, $54 \%$ were males and $46 \%$ females. The greater proportion of pupils had fathers (68.8\%) and mothers (58\%) with PUC/university degree. Completion of the entire questionnaire by the adolescents was ensured by checking for it during the collection of the forms. Despite the checking, some copies of the questionnaire were left unanswered. Incomplete copies were excluded from analysis. The number of responses in the symptom based visits category was very few; hence, it was merged with the $>1$ year to form 'others' during analysis. The demographic data of the subjects are presented in Table1.

Among the demographic variables, parental education was significantly associated with RDA $(\mathrm{P}<0.05)$. Gender and parental occupation were not significantly associated with dental attendance outcome. Twenty percent of children whose mothers had completed primary education, and $30.9 \%$ of children whose mothers had secondary/ degree education visited a dentists recently compared to the $8.9 \%$ of children whose mothers were uneducated. Similarly, $17.9 \%$ children whose fathers had completed only primary education and $30.7 \%$ children whose fathers had completed secondary/degree education visited dentist recently compared to the $3.1 \%$ children whose fathers were uneducated. 
Table 1: Descriptive data of the socio-demographic variables in the study

\begin{tabular}{|llc|}
\hline Variables & & $\mathrm{N}(\%)$ \\
\hline Age & Mean (SD) & $17.51(1.18)$ \\
Sex & Male & $175(54)$ \\
Siblings & Female & $149(46)$ \\
& No siblings & $28(8.6)$ \\
Housing & One sibling & $143(44.1)$ \\
& 2/ >2 siblings & $153(47.2)$ \\
Mothers Education & Hut/combined & $177(54.6)$ \\
& Cement/Brick & $147(45.4)$ \\
& Uneducated & $45(13.9)$ \\
Fathers Education & Primary & $91(28.1)$ \\
& Secondary/degree & $188(58.0)$ \\
& Uneducated & $32(9.9)$ \\
Childhood Dental Visit & Primary & $67(20.7)$ \\
& Secondary/degree & $225(69.4)$ \\
Childhood Dental Experience & Yes & $225(69.4)$ \\
& No & $99(30.6)$ \\
Recent Dental Visit & Bad & $191(59 \%)$ \\
& $<1$ year & $34(10.5 \%)$ \\
& Others & $82(25.3)$ \\
& & $242(74.7)$ \\
\hline
\end{tabular}

A significant association was found (Table 2) between life course factors and dental attendance outcome in bivariate analysis. Housing $(\mathrm{p}<0.05)$, childhood dental visit $(\mathrm{p}<0.001)$ and childhood dental experience $(p<0.001)$ were significantly associated with RDA. Dental coping beliefs were significantly associated with dental attendance $(\mathrm{p}<0.05)$ in the bivariate analysis (Table 3$)$. All the variables found to be significantly associated with dental attendance in bivariate analysis were included in the multivariate analysis.

Table 2: Association between life course variables and recent dental attendance.

\begin{tabular}{|llcccc|}
\hline \multirow{2}{*}{ Variables } & \multicolumn{2}{c}{ Dental attendance outcome } & P value $^{\#}$ \\
& & $<1$ year & Others & Total & \\
\hline Siblings & No siblings & $8(28.6 \%)$ & $20(71.4 \%)$ & $28(100 \%)$ & NS \\
& One siblings & $41(28.7 \%)$ & $102(71.3 \%)$ & $143(100 \%)$ & \\
& Two or more & $33(21.6 \%)$ & $120(78.4 \%)$ & $153(100 \%)$ & \\
Housing & Hut/mud/combined & $57(32.2 \%)$ & $120(67.8 \%)$ & $177(100 \%)$ & $0.002 *$ \\
& Cement/brick & $25(17 \%)$ & $122(83 \%)$ & $147(100 \%)$ & \\
Childhood dental visit & Yes & $79(35.1 \%)$ & $146(64.9 \%)$ & $225(100 \%)$ & $0.001^{*}$ \\
& No & $3(3 \%)$ & $96(97 \%)$ & $99(100 \%)$ & \\
Childhood dental experience & Good & $73(38.2 \%)$ & $118(61.8 \%)$ & $191(100 \%)$ & $0.001^{*}$ \\
& Bad & $5(14.7 \%)$ & $29(87.3 \%)$ & $34(100 \%)$ & \\
\hline
\end{tabular}

*P $<0.05$ considered significant, \#- Chi square analysis 
Table 3: Association between dental coping beliefs and recent dental attendance

\begin{tabular}{|c|c|c|c|c|}
\hline \multicolumn{2}{|c|}{ Dental coping beliefs } & \multicolumn{2}{|c|}{ Recent dental attendance } & \multirow[t]{2}{*}{$\mathrm{P}$ value } \\
\hline & & $<1$ year $(\%)$ & Others & \\
\hline \multirow[t]{2}{*}{ External LOC } & > 33 (High) & $76(48.1)$ & $82(51.9)$ & \multirow[t]{2}{*}{$0.0001 *$} \\
\hline & $<33$ (Low) & $6(3.6)$ & $160(96.4)$ & \\
\hline \multirow[t]{2}{*}{ Internal LOC } & > 31 (High) & $78(49.4)$ & $80(50.6)$ & \multirow[t]{2}{*}{$0.0001 *$} \\
\hline & < 31 (Low) & $4(2.4)$ & $162(97.6)$ & \\
\hline \multirow[t]{2}{*}{ Self-Efficacy } & $>18$ (High) & $81(55.9)$ & $64(44.1)$ & \multirow[t]{2}{*}{$0.0001^{*}$} \\
\hline & $<18$ (Low) & $1(6 \%)$ & $178(99.4)$ & \\
\hline \multirow[t]{2}{*}{ Oral health beliefs } & $>16$ (High) & $50(25.3)$ & $96(65.8)$ & \multirow[t]{2}{*}{$0.001 *$} \\
\hline & $<16$ (Low) & $32(18)$ & $146(82)$ & \\
\hline
\end{tabular}

$* \mathrm{P}<0.05$ considered significant, \#-. Chi square analysis

Results from the multivariate analysis presented in Table 4 shows that participants who lived in cement/brick house were 4.3 times more likely to visit a dentist within one year compared to those living inhut/mud/combined houses $(\mathrm{p}<0.05)$.
Adolescents with low internal $(\mathrm{OR}=0.11$, $\mathrm{P}<0.003)$ and external $\mathrm{LOC}(\mathrm{OR}=0.5, \mathrm{P}<0.001)$, low self-efficacy $(\mathrm{OR}=0.08, \mathrm{P}<0.001)$ had lower chance of visitingthe dentist in a year.

Table 4: Multivariate logistic regression analysis showing adjusted odds ratios with $95 \%$ confidence intervals for recent dental attendance

$* \mathrm{P}<0.05$ is considered significant, R-reference group, Outcome- Recent Dental Attendance, NS-Non Significant

\begin{tabular}{|c|c|c|c|c|c|}
\hline & & Odds & & & $\mathrm{P}$ value \\
\hline & & & Lower & Higher & \\
\hline Housing & Hut/Combined & & & & $0.03 *$ \\
\hline & Cement/Brick $^{\mathrm{R}}$ & 4.3 & 1.14 & 7.8 & \\
\hline Father's education & Secondary/degree & 7.1 & 5.2 & 11.2 & NS \\
\hline & Primary & 1.7 & 0.79 & 3.9 & \\
\hline & Uneducated $^{\mathrm{R}}$ & & & & \\
\hline Mother's education & Secondary/degree & 1.8 & 0.49 & 4.2 & NS \\
\hline & Primary & 1.1 & 0.55 & 2.2 & \\
\hline & Uneducated $^{\mathrm{R}}$ & & & & \\
\hline Childhood dental visit & Yes & 17.3 & 5.31 & 27.8 & $0.001 *$ \\
\hline & $\mathrm{No}^{\mathrm{R}}$ & & & & \\
\hline Childhood dental Exp & Good & 3.6 & 1.34 & 7.62 & $0.01 *$ \\
\hline & $\mathrm{Bad}^{\mathrm{R}}$ & & & & \\
\hline Internal LOC & $\operatorname{High}^{\mathrm{R}}$ & & & & $0.001 *$ \\
\hline & Low & 0.49 & 0.11 & 0.226 & \\
\hline External LOC & $\operatorname{High}^{\mathrm{R}}$ & & & & $0003 *$ \\
\hline & Low & 0.11 & .028 & 0.485 & $0.003^{4}$ \\
\hline Self efficacy & $\operatorname{High}^{\mathrm{R}}$ & & & & \\
\hline & Low & 0.08 & 0.001 & 0.079 & $0.001^{*}$ \\
\hline
\end{tabular}




\section{DISCUSSION}

Our aim in this work was to identify whether life course factors, dental coping beliefs and demographic factors are associated with the 'recent' dental visit among adolescents in Udupi Taluk, India. To the best of our knowledge, this is the first study to look closely into the association between dental coping beliefs, life course factors and recent dental attendance among Indian adolescent population. The findings of this study supported the theoretical relationships that the influence of early life course factors and dental coping beliefs had significant association in determining the 'recent' dental attendance among adolescents.

In this study, dental attendance was associated significantly with parental education. Children whose parents had completed secondary/university degree education were more likely to visit a dentist within one year. This could be explained by the fact that educated parents may be more sensitive to the tangible dental needs of their wards than uneducated parents. Recent dental attendance was not found to be significantly associated with gender in our study. However, Lopez and Baelum (10) found significant differences in the use of dental services among boys and girls.

Dental disease is considered to be a chronic disease. Thus, it is meaningful to study the effect of life course on factors affecting dental diseases; one of the important factors affecting them being regular dental attendance. The type of houses in which the adolescent lived in his/her early childhood and the numbers of siblings when one was 10 years old were used as socio-economic status indicators in early childhood. Financial burden is considered to be one of the main barriers to access to dental care than that of educational standards. However, the findings of our study were peculiar. A greater proportion of children who had lived in huts mud/thatched roof/combined houses in their early childhood visited a dentist recently when compared to those who had lived in a house made of cement/brick. This finding could be explained by the extensive outreach camps for the underprivileged provided by our university for the past 25 years through mobile dental units and various satellite centers in and around Udupi District. Children from lower socioeconomic status have poor oral hygiene and more symptom based visits compared to children from higher socioeconomic status (11), but in our study, the number of adolescents reporting symptom based visits was very few, leading to a limitation of the findings. The statistically significant relationship between childhood dental visit and recent dental attendance further emphasizes the significance of early life experiences on later behavior throughout one's life course. Furthermore, the significant relationship between early childhood dental experiences with 'recent' dental attendance further emphasizes the chain of risk model. The findings are consistent with the studies conducted by $\mathrm{Lu}$ et al (12) and Nicolau et al (13) who reported that a child who visited a dentist in his childhood is more likely to seek dental care in his later life. The findings of thsi study further strengthen and signify the use of life course approach in studying the factors determining dental attendance.

The results of multivariate analysis showed that higher Internal LOC beliefs were consistently associated with recent dental attendance. This finding is in accordance with the findings reported by Bailey et al (14) and Weiss and Diserens (15). External LOC was also found to be higher among those who had regular dental attendance, which contradicts the findings reported by Peker and Bermek (16). The population of the present study demonstrated varied findings with respect to LOC and dental attendance behavior. Internal and external LOC were found to be high among those who visited dentist within one year. According to reports from the literature, higher internal LOC is associated with health promoting behaviors $(17,18)$. Higher external LOC has been found to be associated with adverse oral health behavior and low socioeconomic status (19). Higher selfefficacy was found to be associated with recent dental attendance. Studies have reported that higher self-efficacy correlates with regular dental visits $(20,21)$.

The results of our study also affirm the finding that adolescents whose parents are less educated and who experienced economically disadvantaged circumstances during their childhood have less control over the events which happen in their lives. The DCBS used in this study recognized the attitude of the patient towards the things happening in his/her life. It also identified 
patients' oral health beliefs and self-efficacy in performing oral hygiene practices. DCBS provides a useful insight to the oral health professional regarding the orientation of a patient's belief either in internal or external controls. Studies regarding the association between life course factors and recent dental attendance are very scarce. Prospective study is the desired design to evaluate life course effects on oral health; however, our study found significant relationship which warrants long-term studies to support our findings.

The limitation of this study include the selfreporting method employed to collect information regarding the parents' demographics and life course factors. Further, their level of knowledge can either overestimate or underestimate their own oral health behaviors. DCBS constructs like internal LOC, external LOC, self-efficacy and oral health beliefs were dichotomized for statistical analysis, and some loss of information was inevitable. The cross sectional design fails to establish a causal relationship among the variables. Oral health status is an important component which could influence an individual's dental attendance behavior, which could have been assessed to strengthen the findings. Further research using longitudinal and interventional methodologies is required to establish an association between life course factors, dental coping beliefs and recent dental attendance.

In conclusion, dental coping beliefs, early life course factors and parental education were found to be the major determinants of recent dental visit pattern of adolescents. These socio-behavioral factors should be borne in mind when planning a dental health programme to improve the frequency of dental visit among adolescents. Further, it may also help in providing a useful insight to oral health care professional when motivating individual adolescents towards regular dental attendance patterns.

\section{ACKNOWLEDGEMENT}

No funds were received for conducting this study. We are thankful to all the schools, pupils and teachers for their valuable time and participation. We would also like to thank the late Dr. Shaina Kunder for her support during data entry for this study.

\section{REFERENCES}

1. Kuh D, Ben-Shlomo Y, Lynch J, Hallqvist J, Power C. Life course epidemiology. J Epidemiol Community Health 2003; 57: 77883.

2. Wadsworth MEJ, Kuh DJL. Childhood influences on adult health: a review of recent work from the British 1946 national birth cohort study, the MRC National Survey of Health and Development. Paediatr Perinat Epidemiol 1997; 11: 2-20.

3. Lundberg O. Childhood conditions, sense of coherence, social class and adult ill health: exploring their theoretical and empirical relations. Soc Sci Med 1997; 44: 821-31.

4. Nicolau B, Marcenes W, Bartley M, Sheiham A. A life course approach to assessing causes of dental caries experience: the relationship between biological, behavioral, socioeconomic and psychological conditions and caries in adolescents. Caries Res 2003; 37: $319-26$

5. Thomson WM, Poulton R, Milne BJ, Caspi A, Broughton JR, Ayers KM. Socioeconomic inequalities in oral health in childhood and adulthood in a birth cohort. Community Dent Oral Epidemiol 2004; 32: 345-53.

6. Wolfe GR, Stewart JE, Maeder LA, Hartz GW. Use of dental coping beliefs scale to measure cognitive changes following oral hygiene interventions. Community Dent Oral Epidemiol 1996; 24: 37-41.

7. Attwood D, West P, Blinhorn AS. Factors associated with the dental visiting habits of adolescents in the west of Scotland. Community Dent Health 1993; 10: 365-73.

8. Dasanayake AP, Li Y, Wadhawan S, Kirk K, Bronstein J, Children NK. Disparities in dental service utilization among Alabama Medicaid children. Community Dent Oral Epidemiol 2002; 30: 369-76.

9. Rose D, Pevalin DJ. 'Social class differences in mortality using the National Statistics Socio-economic Classification - too little, too soon: a reply to Chandola'. Soc Sci Med 2000; 51: 1121-27.

10. Lopez R, Baelum V. Factors associated with dental attendance among adolescents inSantiago, Chile. BMC Oral Health 2007; 7: $1-7$. 
11. Edeistein BL.Disparities in Oral Health and Access to Care: Findings of National Surveys.Ambul Pediatr 2002; 2: 41-47.

12. Lu HX, Wong MC, Lo EC, McGrath C. Trends in oral health from childhood to early adulthood: a life course approach. Community Dent Oral Epidemiol 2011; 39: 352-60.

13. Nicolau B, Thomson, WM, Steele JG, Allison PJ. Lifecourse epidemiology: concepts and theoretical models and its relevance to chronic oral conditions. Community Dent Oral Epidemiol 2007; 35: 41-49.

14. Bailey C, Dey F, Reynolds K, Rutter G, Teoh T, Peck C. What are the variables related to dental compliance? Aust Dent J 1981; 26: 4648.

15. Weiss J, Diserens D. Health behavior of dental professionals. Clin Prev Dent 1980; 2: 5-8.

16. Peker K, Bermek G. Oral health: locus of control, health behavior, self-rated oral health and socio-demographic factors in Istanbul adults. Acta Odontol Scand 2011; 69: 54-64.
17. Chase I, Berkowitz RJ, ProskinHM, Weinstein $\mathrm{P}$, Billings R. Clinical outcomes for early childhood caries (ECC): the influence of health, locus of control. EJPD 2004; 5: 76-80.

18. Wallston KA. The validity of the multidimensional health locus of control scales. Journal of Health Psychology 2005; 10: 623-31.

19. Cohen M, Azaiza F. Health-promoting behaviors and health locus of control from a multicultural perspective. Ethnicity \& Disease 2007; 17: 636-42.

20. Mizutani S, Ekuni D, Furuta M, Tomofuji $\mathrm{T}$, Irie K, Azuma $\mathrm{T}$ et al. Effects of selfefficacy on oral health behaviors and gingival health in university students aged 18- or 19years-old. J Clin Periodontal 2012; 39: 84449.

21. Stewart JE, Strack S, Graves P. Development of oral hygiene self-efficacy and outcome expectancy questionnaires. Community Dent Oral Epidemiol 1997; 25: 337-42. 